\title{
"Plis de passage" Deserve a Role in Models of the Cortical Folding Process
}

\author{
Jean-François Mangin ${ }^{1}$ (D) - Yann Le Guen ${ }^{1}$. Nicole Labra ${ }^{1}$. Antoine Grigis ${ }^{1}$ - Vincent Frouin ${ }^{1} \cdot$ Miguel Guevara $^{1}$. \\ Clara Fischer $^{1} \cdot$ Denis Rivière $^{1} \cdot$ William D. Hopkins $^{2} \cdot$ Jean Régis $^{3} \cdot$ Zhong Yi Sun $^{1}$
}

Received: 29 July 2019 / Accepted: 24 September 2019 / Published online: 3 October 2019

(c) The Author(s) 2019

\begin{abstract}
Cortical folding is a hallmark of brain topography whose variability across individuals remains a puzzle. In this paper, we call for an effort to improve our understanding of the pli de passage phenomenon, namely annectant gyri buried in the depth of the main sulci. We suggest that plis de passage could become an interesting benchmark for models of the cortical folding process. As an illustration, we speculate on the link between modern biological models of cortical folding and the development of the Pli de Passage Frontal Moyen (PPFM) in the middle of the central sulcus. For this purpose, we have detected nine interrupted central sulci in the Human Connectome Project dataset, which are used to explore the organization of the hand sensorimotor areas in this rare configuration of the PPFM.
\end{abstract}

Keywords Cortical folding $\cdot$ Sulcal roots $\cdot$ Sulcal pits $\cdot$ Pli de passage $\cdot$ Central sulcus

\section{Plis de passage}

Cortical folding is a hallmark of brain topography whose variability across individuals remains a puzzle. We no longer compare cortical folding patterns to the coils of the small intestine, but deciphering the morphology of a given brain with the standard nomenclature of sulci and gyri is often full of obstacles. Long primary sulci can be split into pieces that can be recombined in nonstandard ways to create unusual folding patterns, which do not show a clear match with this nomenclature (Ono et al. 1990; Regis et al. 2005). In the middle of the nineteenth century, the anatomists inferring the first road maps of the sulci

Handling Editor: Christoph M. Michel.

This is one of several papers published together in Brain Topography on the "Special Issue: Current Opinions in Brain Imaging Methods and Applications".

Jean-François Mangin

jfmangin@gmail.com

1 Neurospin, CEA, Paris-Saclay University, 91191 Gif-sur-Yvette, France

2 MD Anderson Cancer Center, University of Texas, 1515 Holcombe Blvd., Houston, TX 77030, USA

3 INS, CHU La Timone, Aix-Marseille University, 264, rue Saint Pierre, 13385 Marseille, France and gyri of the human brain introduced a concept helping to overcome the difficulties resulting from these interruptions: they described that some interconnecting gyri usually buried in the depth of the main furrows (see Figs. 1,2) can emerge at the surface of the brain in some individuals. The French anatomist Gratiolet coined first the terms "pli de passage" (Gratiolet 1854; Parent 2014). Later on, the buried gyri were called annectant, bridging or transition convolutions in the English literature, and also submerged gyrus, or submerged gyral passage in recent publications (Germann et al. 2005; Zlatkina and Petrides 2010; Huntgeburth and Petrides 2012; Segal and Petrides 2012; Sprung-Much and Petrides 2018). While these plis de passage seem to appear during the earliest stages of development, which shall lead to regard them as candidates for being a distinctive character of the cortex organization, they did not receive a lot of attention. In this paper, we call for an effort to improve our understanding of the pli de passage phenomenon, and suggest that it could become an interesting benchmark for models of the cortical folding process.

To our knowledge, the first comprehensive effort to map the plis de passage throughout the whole human cortex was performed by Jean Régis, a French neurosurgeon, during his MD thesis (Régis 1994) (cf Fig. 3). Each pli de passage reported in his map was inferred from the observation of a frequent interruption of the folding pattern in a specific spatial localization, often consistent with the disconnected 
Fig. 1 Left: drawing of the gyri buried in the walls of a central sulcus which become apparent when the lips of the sulcus are drawn apart (Cunningham 1903). Right: negative prints of five pairs of central sulci visualized from inside the brain and showing different patterns of buried gyri, courtesy of Mangin et al. 2004
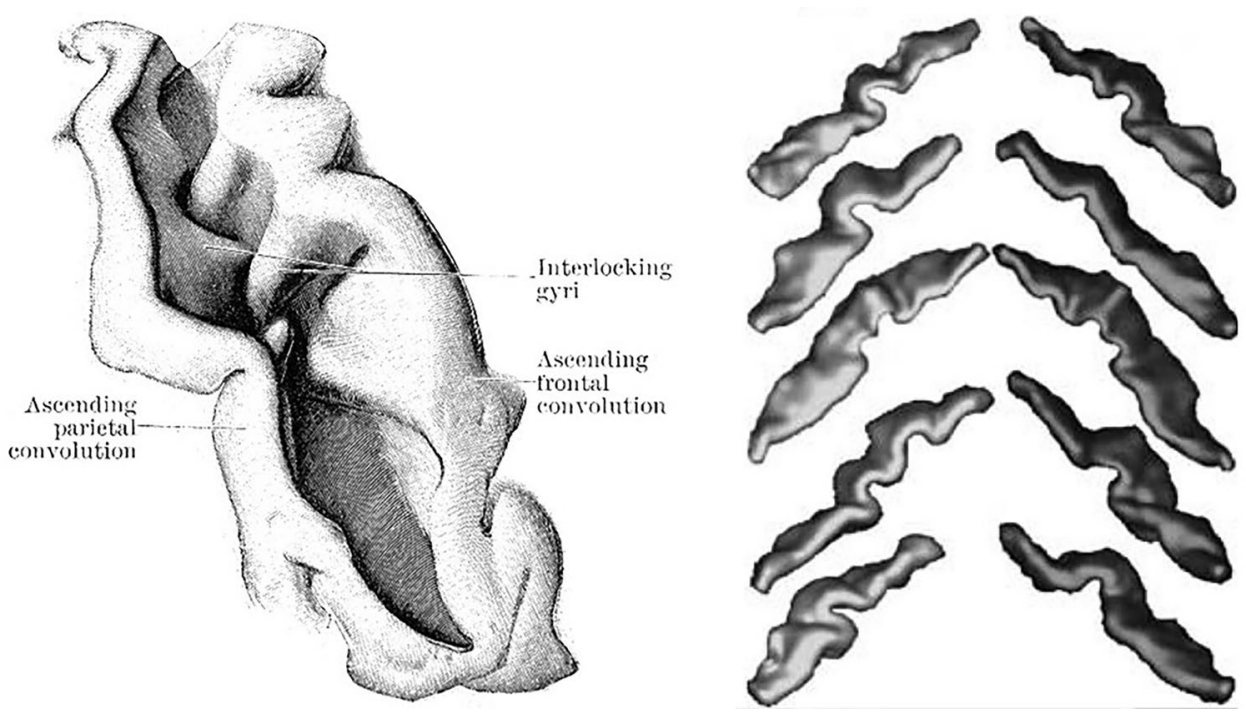
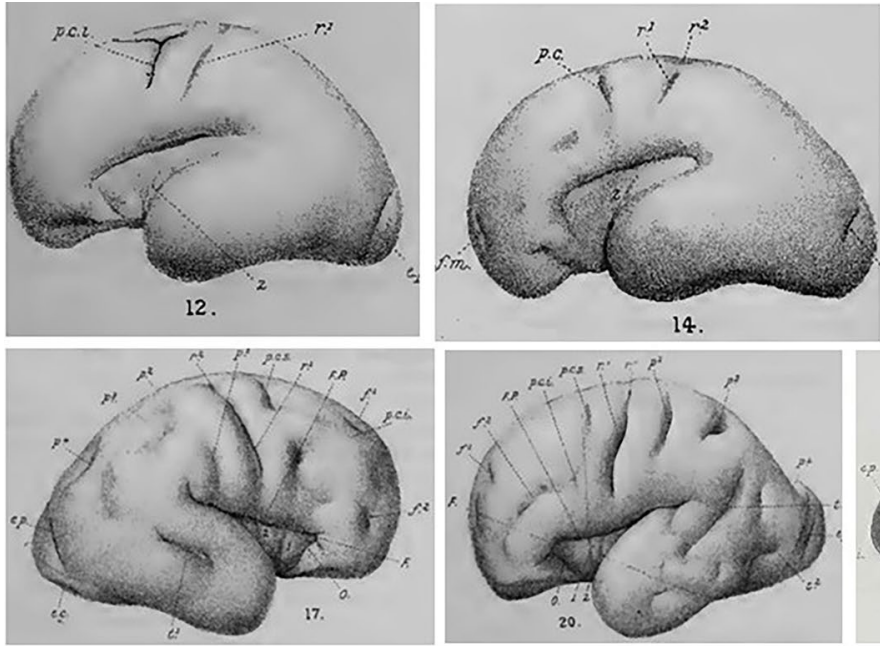

14
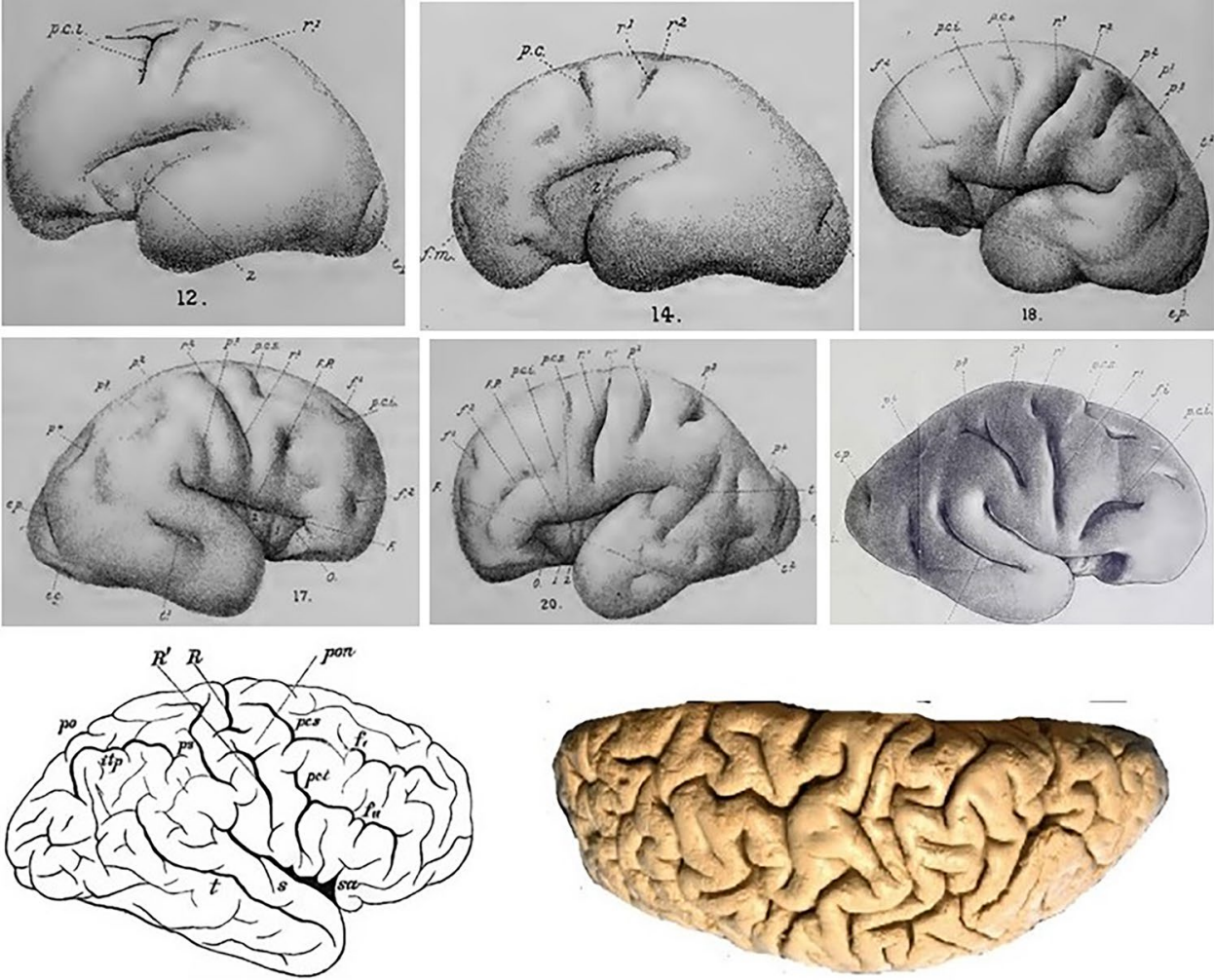

Fig. 2 Top: 6 of the 39 hemispheres collected by D. J. Cunningham between the 5th and 7th months of development, showing the apparition of the central sulcus from two separated folding seeds (Cunningham 1890a, 1897). The lower portion (R1) appears first in the form of a shallow oblique groove which represents the two-thirds of the fully formed sulcus. The upper portion (R2) makes its appearance in the form of a deep pit between the upper end of the lower portion and the

initial folding patterns observed during development (Regis et al. 1997, 2005). In fact, the more usual mode of development of the main sulci is not in the form of a long continuous margin of the hemisphere. A faint furrow often runs over the summit of the elevation separating the two primitive portions. This double seed growing pattern is however not systematic. Bottom: Most of the time, as development goes on, this double seed pattern gets buried in the depth of the fissure, but in less than $1 \%$ of the subjects, the two portions do not merge, as in these 2 examples found in the literature, courtesy of Wagner 1864; Sernoff 1887; Schweizer et al. 2014

groove in the bottom of which plis de passage make their appearance latter on, but in the form of distinct and isolated pieces (Cunningham 1892) (see Fig. 2). The bridges 

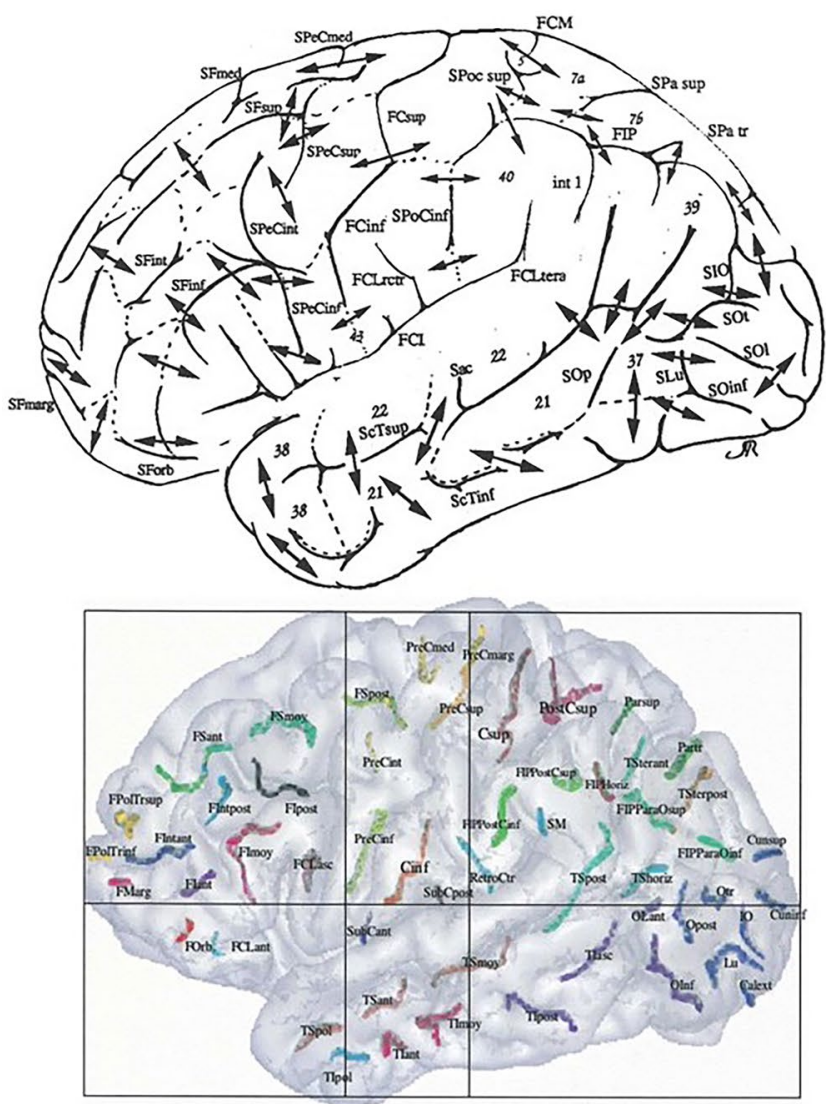

Fig. 3 Top and lower right: Map of the plis de passage denoted by double arrows (aggregation of drawing of Jean Régis (1994)), Lower left: Map of the sulcal roots separated by superficial or buried gyri,

of cortex which intervene between the isolated portions of a developing sulcus are ultimately buried down as the pieces run into each other; but they are not, as a rule, completely obliterated. In the bottom of the fissures they still show as deep annectant gyri (see Fig. 1).

While the map of the plis de passage is a very useful guideline when trying to decipher the idiosyncrasies of individual brains, the design of algorithmic strategies to manipulate explicitly the cortical folding patterns required to flip the concept, in order to deal with folds rather than gyri. In fact, the cortical gyri are difficult to define explicitly because of the lack of elementary building blocks: the gyri are in continuity with each other, which prevents to give them a straightforward geometrical definition fitting any configuration, especially with regard to the interruptions of the main furrows.

\section{Sulcal Roots and Sulcal Pits}

Hence, in the nineties, computational anatomy focused on the cortical sulci, especially the main furrows, which are made up of aggregations of elementary folds with simple
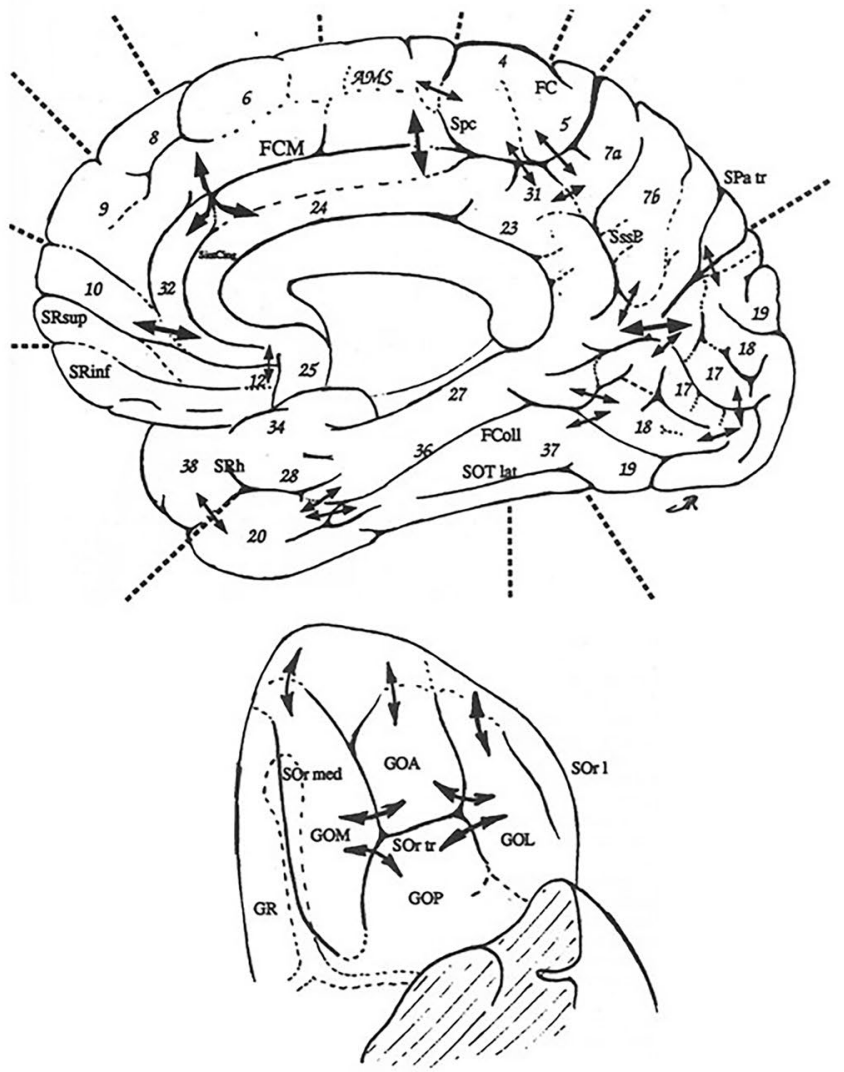

courtesy of (Regis et al. 2005). Names are abbreviations of a French nomenclature of sulci and sulcal roots. Numbers refer to Brodmann areas

geometric definitions (Mangin et al. 2015a, b). Note however recent attempts at defining gyrus-based building blocks of the folding patterns (Chen et al. 2017; Duan et al. 2017). Modeling the cortical sulci and their interruptions led to define a new map based on the concept of sulcal roots (Régis 1994; Regis et al. 1997, 2005) (cf Fig. 3). Conceptually, the sulcal roots are entities supposed to correspond to seeds of the folding process disseminated across the cortical surface. The sulcal root dual map was inferred from the map of the plis de passage from a virtual configuration where each pli de passage is reaching the surface of the brain, creating a local interruption of the folding pattern. Then the sulcal roots can be represented by the connected components of the folding pattern in this virtual map endowed with the maximum number of interruptions. Some of the sulcal roots can be observed explicitly in utero at the first stage of the folding, but this is far to be systematic.

The concept of sulcal roots is very powerful for designing generative "grammatical" models, which can father any folding pattern configuration. In a way, these sulcal roots correspond to some kind of letters supposed to appear only one time in each brain, and the main sulci correspond to 
words made up from these letters and corresponding to the most frequent connections observed in the general population. Then, in the single brain template framework proposed by most anatomy books, each sulcal root is used in only one word of the nomenclature. But dealing comfortably with unusual folding patterns may require an extended vocabulary (Mangin et al. 2016). Several very interesting proposals of extended glossary based on regional folding patterns have been proposed (Steinmetz et al. 1990; Germann et al. 2005; Zlatkina and Petrides 2010; Huntgeburth and Petrides 2012; Segal and Petrides 2012; Plaze et al. 2015; SprungMuch and Petrides 2018; Snyder et al. 2019): each reported pattern often corresponds to a specific configuration of the regional plis de passage, leading to alternative connectivity of the regional sulcal roots. This pattern glossary can be used to perform a subdivision of the population relative to the geometry of the cortical morphology. The hope is that such a subdivision provides a proxy to architectural differences. In the future, unsupervised clustering may contribute to the inference of a comprehensive dictionary of the folding patterns (Sun et al. 2007, 2009; Duan et al. 2019).

Because of the lack of data about the early stages of the normal folding dynamics, however, testing whether sulcal roots are reproducible and actually correspond to a key element of the folding process is difficult. Highly premature birth occurring at the early stage of the folding process is a very attractive source of data, but cannot be considered as normal development (Dubois et al. 2008; de Vareilles et al. 2019). The development of in utero imaging could rapidly change the situation (Lefèvre et al. 2015; Makropoulos et al. 2018). Furthermore, longitudinal acquisitions could lead to explore further the idea that the folding dynamics embed some kind of seeds with higher folding speed (Lefèvre et al. 2009; Xia et al. 2019).

Nevertheless, sulcal roots are mainly a concept used to decompose the folding dynamics. Hence sulcal root maps are difficult to match with the actual cortical folding patterns. Therefore, the community has moved to the notion of sulcal pits, the locally deepest points of the cortical surface, also corresponding to the local depth maxima along the bottom lines of the sulci (Lohmann et al. 2008; Im et al. 2010; Auzias et al. 2015). Intuitively, these deepest points could correspond to the places where the folding process begins and be intimately associated with the concept of sulcal roots. This is however also very difficult to test. Anyway the exact location of the roots in the folding pattern is not a crucial issue. The key contribution of the sulcal root/pit idea is the possibility to decompose the global sulcal pattern into reproducible building blocks overcoming the interruptions of the main sulci. An alternative but similar approach consists in decomposing the cortical surface into basins inspired by the watershed geographical notion (Lohmann and von Cramon 2000; Kruggel 2018). Sulcal pit maps have been inferred from large populations (Lohmann et al. 2008; Im et al. 2010; Auzias et al. 2015) including infants (Meng et al. 2014; Im and Grant 2019), highlighting strong similarities with the sulcal root maps and a striking reproducibility across populations and ages. It is now possible to quantify sulcal pits heritability, which ranges between 0.2 and 0.5 (Le Guen et al. 2018a). In a near future, sulcal pits configurations could be related to genetic variants providing insight into neurodevelopmental disorders (Ortinau et al. 2018; Im and Grant 2019).

\section{Mechanical and biological folding models}

Why the cerebral cortex folds has fascinated and mystified some neurobiologists for a long time (Cunningham 1890c; Welker 1988; Van Essen 1997; Striedter et al. 2015). A large variety of intuitive generative mechanisms have been proposed but most of them have been dismissed during the last decades to give rise to a modern twofold vision of the phenomenon (Llinares-Benadero and Borrell 2019). The first point of view is purely mechanical, modeling the old intuition that the outside layer of the cortex increases by surface extension at a pace that cannot be compensated without folding by the slower volumetric extension of the inner part (Jelgersma 1889; Cunningham 1890c; Richman et al. 1975; Toro and Burnod 2005). Recent theoretical developments along that line have shown that realistic folding geometries can be obtained from simulations of the mechanical instability driven by the tangential expansion of the grey matter of the cortical mantle (Tallinen et al. 2014, 2016). Further theoretical developments aim at refining the mechanical modeling taking into account for instance the stiffness and elasticity of the different tissues (Kroenke and Bayly 2018; da Costa Campos et al. 2019).

An interesting question is whether a simplistic mechanical process is sufficient to generate some global features like the principal directions of the folds, which share striking similarities with meridian and parallel on earth (Régis 1994; Toro and Burnod 2003; Regis et al. 2005; Clouchoux et al. 2010; Auzias et al. 2013), or the folding wavelength that can be observed for instance in the periodicity of the sulcal pits in the meridian and parallel directions. The folding wavelength is clearly related to cortical thickness, which explains some of the cross species variability (Toro and Burnod 2005; Mota and Herculano-Houzel 2015; LlinaresBenadero and Borrell 2019). An extreme mechanical point of view leads to consider that the folding pattern could be mainly related to the initial geometry of the cortex (Bohi et al. 2019) and a few parameters like cortical thickness, the differential of expansion between grey and white matter, and mechanical properties. Hence it is sometimes speculated that the meridian/parallel organization could simply result from 
the directions of the two principal curvatures of the smooth cortical surface (Tallinen et al. 2016). It is even proposed that "mechanical morphogenesis", namely the capacity of homogeneously growing elastic tissue to produce complex shapes, could play an important role in the segregation of the neocortex through the exploitation of the modules defined by the folding pattern (Foubet et al. 2018; Heuer and Toro 2019).

While the modern mechanical models represent an important step forward, none of them can generate the stereotyped folding pattern of the human cortices featured for instance in the sulcal pit map. It is difficult to believe that this will happen as long as the mechanical models rely on parameters spatially homogeneous throughout the cortical surface. Spatial and temporal heterogeneities, for instance in the expansion differential between the outer layer and the rest of the cortex, seem mandatory to select a specific reproducible pattern from the infinite number of attractors of the folding dynamics. Hence, a key issue is the biological substrates of the expansion differential (Borrell 2018; Kroenke and Bayly 2018). This is still a relatively open issue, but major advances have occurred during the last decade (LlinaresBenadero and Borrell 2019). The rapid tangential growth of the outer layer is probably strongly related to the differentiation of the neurons of the cortical plate, the growth of their cell bodies and of the surrounding neuropil (formation of axons, dendrites and synapses) (Wang et al. 2017). Hence, the microstructural differences across architectonic areas and their various maturation timelines probably father some heterogeneities in the maps of expansion differential across the cortical surface.

But before all, It seems that some variations in the initial packing of the neurons in the cortical plate existing after the migration from the subventricular zone gradually disappear during the tangential expansion leading to folding. Provided that these packing heterogeneities are similar across individuals, the higher expansion rate of the high neuron density areas may explain the existence of systematic seeds of folding in the spirit of the sulcal root concept. It has been shown that the variations in the packing of neurons originate from neurogenesis and neuron migration and are specific to folded mammal species (Kriegstein et al. 2006; Reillo et al. 2011; Borrell and Calegari 2014). Some regions of the subventricular zone enjoy higher neurogenesis rates, which result into greater surface expansion after the neuron migration into the cortical plate. Note however that the mechanism underlying the surface expansion may be more complex than what is embedded in the current mechanical models: progenitor cells located in intermediate zones of the subplate could lead to a tangential dispersion of the neurons occurring already during their radial migration rather than only from the cortical plate expansion (Llinares-Benadero and Borrell 2019). To conclude, it seems that the chronology of activity of the different sulcal roots may be strongly related to the chronology of neurogenesis.

A "protomap" of the primary folding pattern seems to exist at the level of the subventricular zone, before the neuronal migrations leading to the construction of the cortical mantle take place (de Juan Romero et al. 2015). This protomap, which is assumed to result from heterogeneous gene expressions, could be the primal sketch of both the differentiation of the cortex into architectonic areas and the primary folding pattern (Kostovic and Rakic 1990; Sur and Rubenstein 2005; Reillo et al. 2011). It would be really fascinating to be able to test whether the grid of sulcal pits/roots of the human brain is related to alternating blocks of high and low genetic expression patterns in the meridian and parallel directions (Lui et al. 2011; Albert and Huttner 2015; de Juan Romero et al. 2015). Since protogyral areas of the protomap, which will become gyri, correspond to an increased multiplication of neurons, they may contain the expansion maxima responsible for selecting the primary attractor in the folding dynamics. Therefore, by combining the mechanical model derived by the physicists with the protomap model from biology, simulations could resemble actual brains.

\section{Back to the plis de passage}

Sulcal pits, sulcal basins and sulcal roots correspond to a wide variety of local folding geometries: a focal pit, an elongated groove, a T-shape configuration, or a more complex cushion button configuration. This variability in appearance is probably resulting from the variety of geometrical configurations of the seeds of higher tangential expansion surrounding them. Our building blocks of the folding patterns look like pieces of the boundaries of a parcellation of the cortex, and not like elementary architectural modules coded in the protomap or emerging from cortical maturation. Therefore it is tempting to flip back the point of view from folds to gyri, to try to pinpoint building blocks of the cortical morphology that would be easier to relate to the modern biological models of the folding process. Plis de passage are very good candidates even if they account only for a small part of the whole gyral morphology: they have a very focal localization, a clear geometry and they present a striking variability across individuals that has to be explained by the models. Each pli de passage may be related to one elementary feature of the protomap or of the cortical architecture.

Very few plis de passage have been studied in the literature. Therefore, in the following, we will focus on the PPFM, the "pli de passage frontal moyen", described initially by Broca as a bulge into the middle of the central sulcus (Broca and Pozzi 1888). Later on, Cunningham spoke about a shallowing of the fissure and a deep interlocking of its adjacent walls (see Fig. 1) (Cunningham 1892; White et al. 1997). 
According to him, two of the interdigitating gyri are supposed to be always larger and more pronounced than the others, and in a considerable number of cases they unite at the bottom of the sulcus in the form of a distinct deep gyrus, which constitutes a marked interruption in its floor. All gradations between a mere shallowing with an interlocking of the adjacent walls of the fissure and the presence of a distinct deep annectant gyrus are met with.

The PPFM has become a subject of interest with the advent of functional imaging, because several studies have shown striking relationships with the hand sensorimotor areas (Yousry et al. 1997; Sastre-Janer et al. 1998; Boling et al. 1999; Boling and Olivier 2004). Note that the PPFM gathers two entities, a gyrus located in the precentral (frontal) wall of the central sulcus, supposed to be mainly associated to the motor hand area (Boling et al. 1999), and a gyrus located in the postcentral (parietal) wall of the central sulcus, supposed to be mainly associated to the sensory hand area (Boling and Olivier 2004). The neuroimaging community frequently uses the terms "hand knob" to denote the omegashaped knob observed in the central sulcus in MRI axial sections and corresponding to the motor precentral part of the PPFM (Yousry et al. 1997). In some subjects, the knob has the shape of an epsilon in the MRI axial sections, which may correspond to configurations where it is shaped by two buried gyri located in the precentral wall of the sulcus. To our knowledge, the exact localization of the hand motor area for epsilon configurations has not been described yet.

Knowing now that the buried PPFM has a clear meaning relative to functional architecture, let us go back to its formation according to Cunningham (see Fig. 2) (Cunningham 1890c, 1897). Note first that Cunningham's description of the development of the central sulcus is inferred from the observation of 39 hemispheres of his collection. Hence his "developmental movie" is purely virtual, based on some kind of mental interpolation, and can be questioned. In many cases, central sulcus arises in the form of a continuous groove, which is steadily deepen by the upheaval of its bounding banks. But frequently, it takes origin in two portions. Of these the lower and longer part makes its appearance first as a continuous groove. The upper part has an independent origin. It first shows as a slight depression, which widens and deepens and is separated from the lower part of the furrow by a high bridge of cortex. A faint groove then runs over the surface of this bridge and connects the two parts. In course of time the bridge disappears from the surface as the connecting groove cuts deeper and deeper into it, but in the after-growth of the brain it is retained in the form of an annectant gyrus. In very rare cases the two original portions of the central sulcus remain distinct throughout life, and the intervening bridge of cortex remains on the surface. Heschl, who examined 2174 hemispheres, found the interrupted form of the central sulcus only six times
(Heschl 1877). Eberstaller met with it twice in 200 brains (Eberstaller 1890). A few other cases were reported in the literature (Schweizer et al. 2014), but the general impact seems around only $0.5 \%$ of the hemispheres.

Let us now try to interpret the development of the PPFM in the light of the modern biological models of cortical folding. This interpretation will be pure speculation, but the goal is to highlight the kind of hypotheses that could be put forward when trying to model the pli de passage development. The first event of the chain is the birth of the lower sulcal root of the central sulcus, a priori resulting from the tangential expansion of at least one of the two protogyri, which will sculpt the sulcus (precentral and postcentral), and a priori mainly in the direction orthogonal to the sulcus. According to Cunningham, the postcentral gyrus shows a "greater growing energy" than the precentral gyrus, which results in a tilt of the central sulcus orientation (Cunningham 1890b). Then, in some subjects, the lower sulcal root elongation toward the top of the brain is stopped by a piece of cortex bridging between the precentral and the postcentral gyri. This bridge seems endowed itself with a tangential expansion, maybe perpendicular to the first one, that can compete with the expansion generating the lower root. Later on, the folding action of this first expansion phenomenon, which seems to follow a chronological gradient from the bottom to the top of the brain, reappears at the level of the upper root. Most of the time, this initial expansion finally becomes faster than the second one leading to a fusion of the two sulcal roots.

The speculation above raises several questions about the origin of the expansion phenomena. The expansion of the precentral and of the postcentral gyri seem to be a primary phenomenon, which is a good candidate for being encoded in the genetic protomap. The very same pattern is observed in all primates (Heuer et al. 2019) and corresponds to the building of the primary motor and somatosensory systems. It is less clear why the hand areas would grow earlier or faster than the surrounding areas. It could be related to heterogeneities in the developmental trajectories of the sensorimotor subsystems across the body, the hand being an early bird. Cunningham himself suggested that the cortex must grow in accordance with the functional activity that is displayed in its different parts, leading to heterogeneities of the surface extension (Cunningham, 1890b, c). Hence, one may assume that the neuropil of the hand areas is developing earlier or faster, leading to the apparition of the bridging gyrus. Note that in a population born with a missing hand, it was observed that the contralateral central sulcus was often flat, without clearly demarcated hand knob (Sun et al. 2017).

An alternative hypothesis is the existence of a hand-dedicated neuron proliferation area in the protomap. Note that whenever the meridian/parallel organization of the sulcal roots corresponds to a grid-like 2D pattern in the protomap, 
it would make sense to have parallel axes of neuron proliferation orthogonal to the meridian axes corresponding to the precentral and postcentral gyri. Cunningham stressed the fact that the central sulcus development must be related to the development of the other two meridian sulci, the precentral and the postcentral sulci, which appear in two distinct pieces (Cunningham 1890b). It seems that an axis of neuron proliferation may cross in the middle of the three meridian sulci. Note also that the "hand knob" is clearly shaped in great apes but not in old world monkeys, which may rely on a genetical origin (Hopkins et al. 2014). Finally, when describing the central sulcus, Broca mentions three plis de passage (Broca and Pozzi 1888) (cf Fig. 3): the PPFM in the middle and two other plis above and under the sulcus, which may belong to two other axes in the same parallel direction. A grid-like protomap based on a simple 2D morphogenesis system may be underlying the folding process.

\section{Interrupted Central Sulci}

It is interesting to extrapolate the above speculations to the rare cases of central sulcus interruptions. What could happen in case of very active expansion of the bridging gyrus is the apparition of a T-shape configuration at the end of the lower central sulcus root, definitively forbidding the connection with the upper root. A reversed T-shape could also appear at the bottom of the upper sulcal root. It seems to be the configuration observed for the two hemispheres of Fig. 2.

Interrupted sulci provide the opportunity to explore further the links between the bridging gyrus and the hand sensorimotor areas. What about configurations where this gyrus reaches the surface of the brain? If the bridging gyrus is really created by the growth of the hand sensorimotor area, the link should be preserved even in extreme configurations. To our knowledge, the literature includes only one case of interrupted central sulcus with fMRI-based sensorimotor mapping, but the results reported in 2D are difficult to interpret (Alkadhi and Kollias 2004). Therefore, we decided to look for interrupted central sulci in the outstanding Human Connectome Project dataset (Van Essen et al. 2012, 2013; Glasser et al. 2013). Subjects were chosen by the HCP consortium to represent healthy adults beyond the age of major neurodevelopmental changes and before the onset of neurodegenerative changes. All subjects provided written informed consent on forms approved by the Institutional Review Board of Washington University. We used the 820 subjects from the HCP-S1200 release labelled as Caucasian and already processed for a heritability study (Le Guen et al. 2018b). This set of 820 subjects raised the hope to fish about 8 interrupted central sulci. Furthermore, the HCP rich dataset provided us with the opportunity to validate the identification of interrupted central sulci using simple fMRI contrasts delivered by the consortium, mapping the hand, the foot and the tongue sensorimotor systems (Woolrich et al. 2001; Jenkinson et al. 2002; Feinberg et al. 2010; Moeller et al. 2010; Barch et al. 2013). Participants were presented with visual cues that ask them to tap their left or right fingers, squeeze their left or right toes, or move their tongue.

Since the central sulcus is usually not interrupted and relatively easy to identify, the study of the PPFM has often been performed using profiles of depth along the bottom line of the sulcus (Cykowski et al. 2008; Hopkins et al. 2010; Coulon et al. 2011; McKay et al. 2013; Hopkins et al. 2014; Schweizer et al. 2019). The rare cases of central sulcus interruption require a different strategy, all the more that the central sulcus automatic recognition may be problematic for such configurations. We leveraged a new approach developed to study asymmetry and heritability of the main plis de passage (Le Guen et al. 2018b).

The sulcal pit map was detected first in each brain of the HCP dataset (Auzias et al. 2015) using the Cortical Surface toolbox of BrainVISA (http://brainvisa.info) applied to the meshes of the cortical surface computed with Freesurfer from the T1-weighted MRI (Fischl 2012; Le Guen et al. 2018b). Depth profiles were computed between the two main sulcal pits of the central sulcus (Le Guen et al. 2018b). Finally, the PPFM was detected as a significant depth minimum. Hence, rather than inspecting visually the 1640 hemispheres, we selected only the hemispheres with a candidate PPFM less than $5 \mathrm{~mm}$ deep, which corresponded to about $1 \%$ of the dataset. Each T1-weighted MRI was also processed using the Morphologist toolbox of BrainVISA, in order to extract the pial surface, the white matter surface, and a negative mold of the central sulcus used for visualization (Fischer et al. 2012). Half of the selected hemispheres were discarded because the central sulcus was clearly not interrupted. The candidate PPFM was an artefact probably resulting from a misalignment with Freesurfer template creating a spurious interruption. Note that only $0.5 \%$ of the hemispheres were clearly misaligned at the level of the central sulcus, which is without consequences in most neuroimaging studies. We were left with nine hemispheres with a complete interruption of the detected central sulcus. To validate the identification of the two pieces of the central sulcus, we used the connectome Workbench viewer of the HCP project (Marcus et al. 2011) to confirm that the foot, hand and tongue sensorimotor activations were located along the central sulcus (see Fig. 4), which happened for the nine hemispheres. For this visualization, we used the fMRI individual contrasts provided by the HCP consortium for a decimated version of the cortical surface mesh. To clarify the content of these three contrasts, we also computed an average across the 900 first subjects delivered by the HCP consortium (second release). For this purpose, we first aligned all the central sulci using the ICP algorithm (Sun et al. 2016, 2019). Then we projected the 


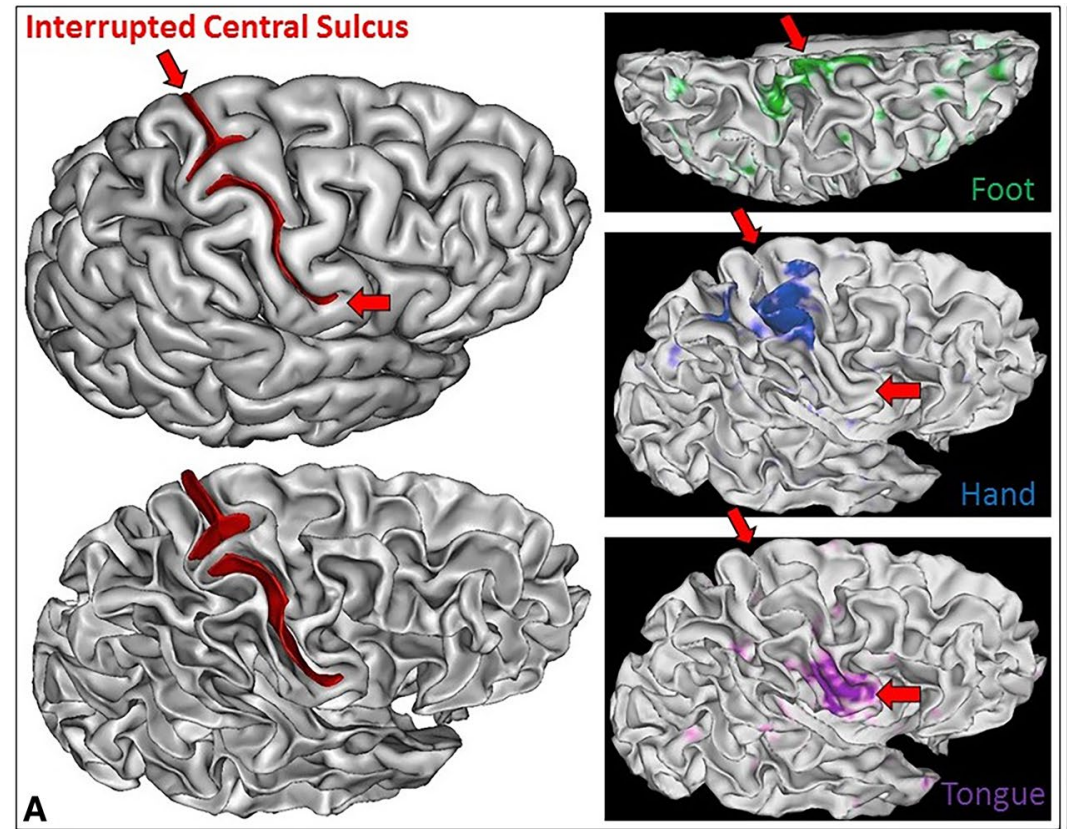

\section{Average (900 subjects)}

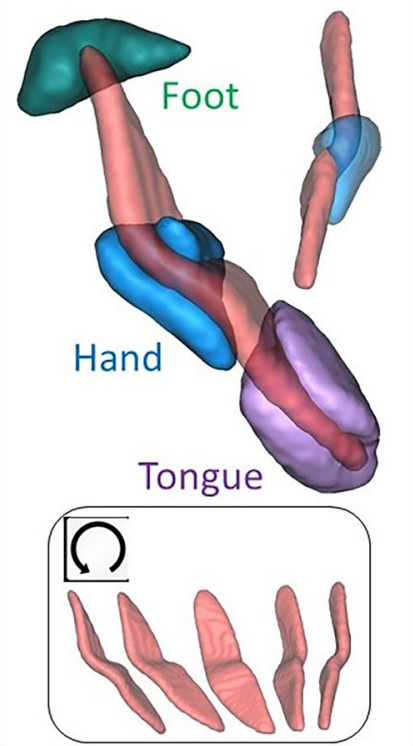

Fig. 4 Left: one of the nine hemispheres of the HCP dataset with an interrupted central sulcus (BrainVISA viewer in the left, Connectome WB viewer in the middle). The foot, hand and tongue sensorimotor contrasts are used to validate the central sulcus identification (reported from BrainVISA viewer with the red arrows). Right: Average of the three sensorimotor fMRI contrasts computed from about 900 subjects after central sulcus alignment
Fig. 5 The two left hemispheres of the HCP dataset with an interrupted central sulcus. The two first lines are provided by Anatomist, the viewer of BrainVISA. The bottom line is provided by the Connectome Workbench viewer for the hand sensorimotor contrast
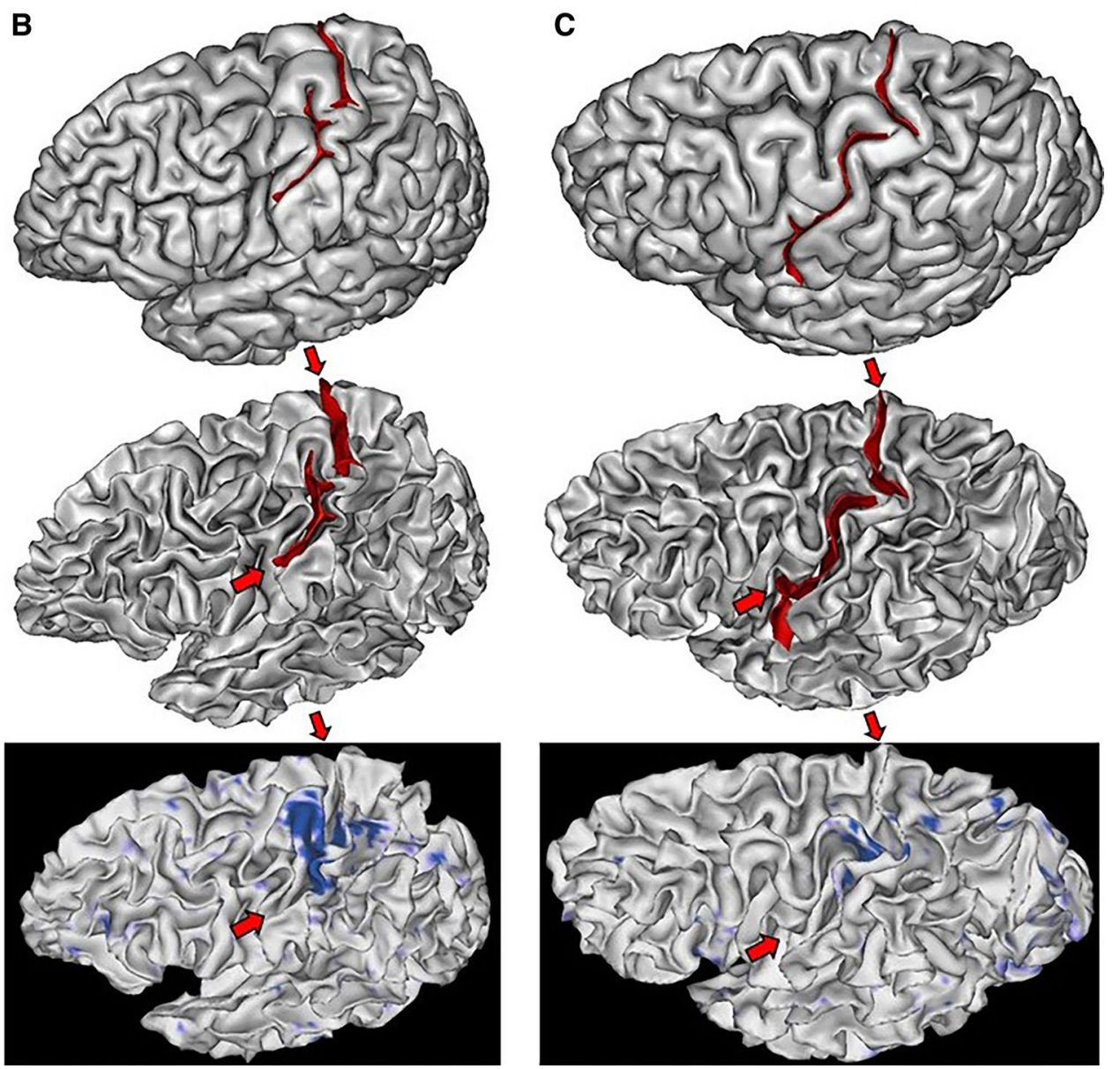
Fig. 6 Six of the seven right hemispheres of the HCP dataset with an interrupted central sulcus. The two first lines are provided by Anatomist, the viewer of BrainVISA. The bottom line is provided by the Connectome Workbench viewer for the hand sensorimotor contrast
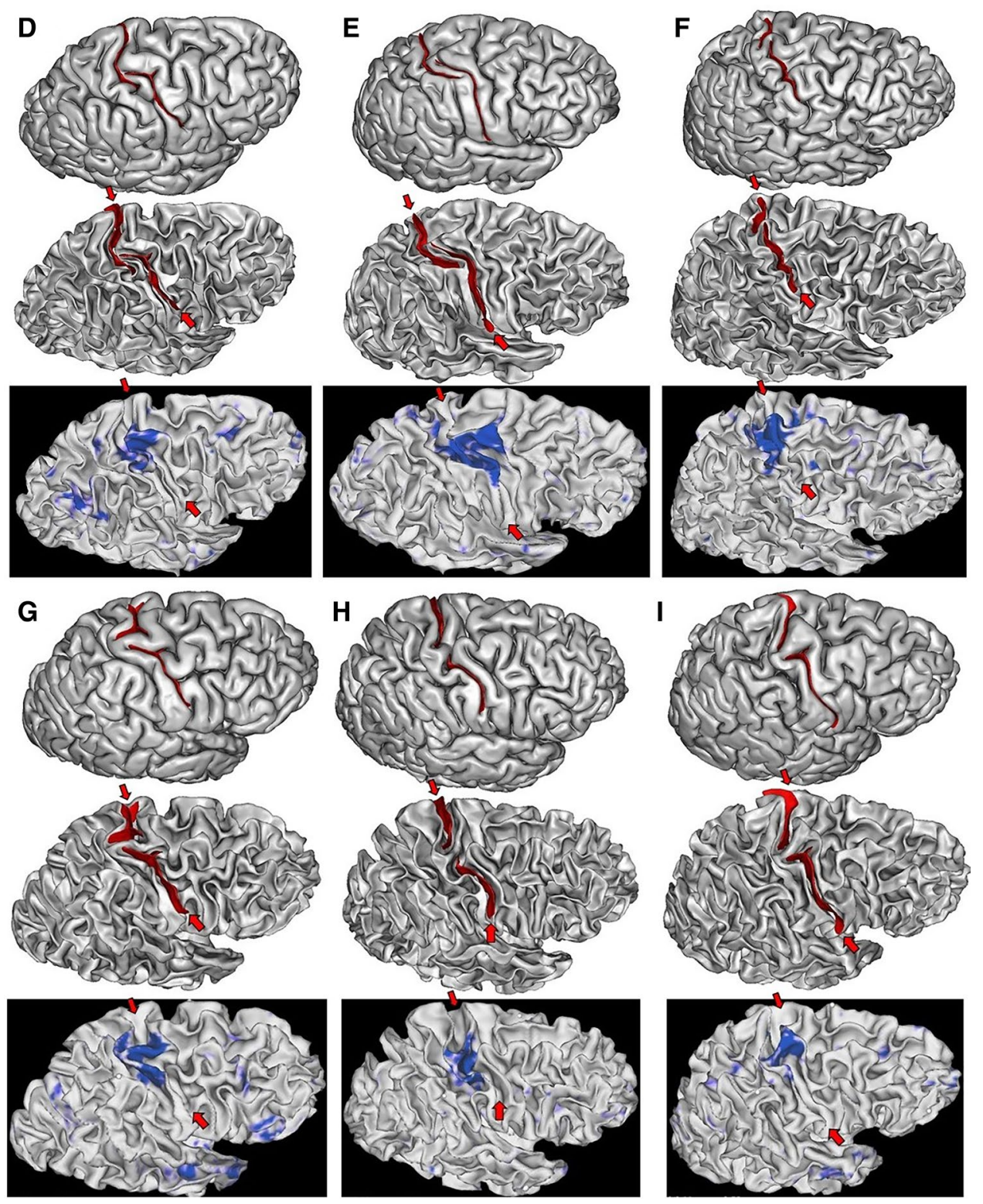

vertices of the cortical surfaces of all the subjects in the same space to compute an average (see Fig. 4). For the nine hemispheres, we could observe that the individual hand sensorimotor contrast in the central sulcus region was very similar to the average contrast of Fig. 4. Furthermore, the hand areas were clearly located in the bridging gyrus and extended downward in the postcentral gyrus like in the average (see Figs. 5, 6).

While the shape of the average central sulcus of Fig. 4 is very smooth, the association between the precentral motor side of the activation with the hand knob is clear. It was shown before using a manifold-based shape analysis that this association holds whatever the position of the knob along the central sulcus, which can vary from the middle of the sulcus to the upper two-thirds of the sulcus (Sun et al. 2016).
The sensory side of the activation is much more elongated, covering the middle third of the postcentral gyrus, reaching much lower than the motor side. It should be noted that in the standard buried PPFM configuration, the gyrus buried in the postcentral wall is usually located lower than the gyrus buried in the precentral wall. Without fMRI tagging of these buried gyri, however, this observation is questionable, because other interdigitations can be observed in the central sulcus (see Fig. 1). The visualization of the average central sulcus from inside the brain (under the sulcus) highlights its twofold geometry. The hand sensorimotor activation seems located exactly where the two parts of the sulcus merge, which is supposed to be the localization of the deepest part of the PPFM. 
Fig. 7 A chimp brain with central sulcus interruption in the left hemisphere
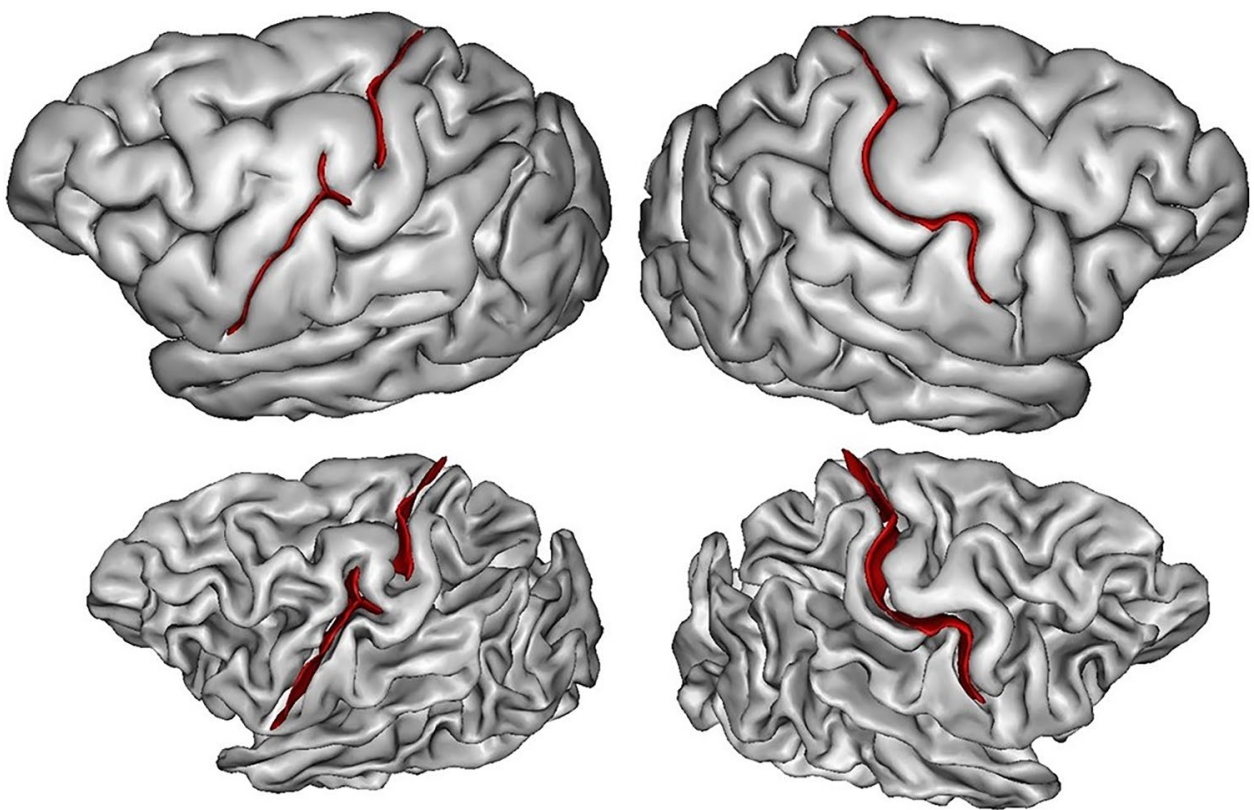

We propose our visualizations of the nine hemispheres in Figs. 4, 5, 6, in order to allow observations of the folding pattern surrounding the central sulcus. It is the first time that several brains with this rare configuration are gathered. It is interesting to explore to which extent this configuration is a proxy for more global specificities. Some of the hemispheres present the "T-shape stop signal" observed in Fig. 2, but it is not systematic. It seems that some configurations correspond to cases where the two sulcal root were not able to meet. In such situations, the roots get much more elongated than usual (cases D \& E). We found two interruptions in the left hemisphere versus seven in the right hemisphere, but this unbalanced result has to be reproduced.

The clear relationship between the PPFM and a regional feature of the cortical functional organization calls for a systematic exploration of the potential meaning of the other plis de passage. Interesting candidates are the plis de passage interrupting the Superior Temporal Sulcus, which are more developed in the left hemisphere, hinting at a link with the language system (Ochiai et al. 2004; Glasel et al. 2011; Segal and Petrides 2012; Leroy et al. 2015; Le Guen et al. 2018b). Another language-related area of interest is Broca's area, where a submerged gyral passage can often be found separating the sulcus diagonalis from the neighboring sulcus (Sprung-Much and Petrides 2018). A number of plis de passage impacting the geometry of the precentral and the postcentral gyri would also be interesting targets (Germann et al. 2005; Amiez et al. 2006; Zlatkina and Petrides 2010; Zlatkina et al. 2016).

\section{Conclusion}

The plis de passage appear in the earliest stages of development. Therefore, they should be regarded as a deep-seated character of the cortical organization that could help us to decipher the mechanisms driving the cortical folding process. The origin of the variability of their depth is unclear, but our speculations on the PPFM lead to a simple hypothesis: when the tangential expansion creating the bridging gyrus occurs early enough relative to the orthogonal expansion fathering the main sulcus, the pli de passage can resist burial, for instance thanks to T-shape local folding patterns. This chronological hypothesis may lead to think that the depth of the plis de passage is just an epiphenomenon. A recent result, however, has shown that a superficial pli de passage in the visual word form area has a positive impact on reading skills (Cachia et al. 2018).

Much more work is required to reveal the nature of the buried gyri. For instance, while the tension-based theory of D. Van Essen to explain the folding pattern has been set aside regarding primary sulci (Van Essen 1997; LlinaresBenadero and Borrell 2019), fiber-based constraints may be one of the drivers of secondary and tertiary folding. Hence, the potential relationships between plis de passage and U-fiber bundle organization is a very attractive research program (Mangin et al. 1998; Pron et al. 2018; Bodin et al. 2019). U-fiber organization must be impacted by the depth of plis de passage. Furthermore, the depth of a pli de passage may have an impact on the connectivity arising from the exuberant proliferation of axons occurring during development: the existence of a pli de "passage" reaching the brain 
surface may increase the amount of axons connecting the functional areas located on both side of the sulcus.

It would be also interesting to clarify whether some of the plis de passage are specific to humans. Cunningham mentioned in his seminal work that he did observe some of the plis de passage in chimp and orang brains (Cunningham 1890b). Browsing the chimp brain collection of W. Hopkins, we found a quasi-interrupted central sulcus (see Fig. 7). Hence, there may exist a marked tendency in the human brain towards the breaking up of the main sulci into two or more component parts by the formation of deep or superficial annectant gyri, but it may just be related to brain size. It would be interesting to test to which extent the pli de passage phenomenon is impacted by the folding allometries reported in the past (Toro et al. 2008; Germanaud et al. 2012, 2014).

Acknowledgements This work was partially funded by the Human Brain Project, funded from the European Union's Horizon 2020 Framework Programme for Research and Innovation under the Specific Grant Agreements No. 785907 (SGA2) and No: 604102 (SGA1), by the FRM DIC20161236445, and by the Blaise Pascal Chair from Région Ile de France and COMUE University Paris-Saclay to W. Hopkins. Data were in part provided by the Human Connectome Project, WU-Minn Consortium (Principal Investigators: David Van Essen and Kamil Ugurbil; 1U54MH091657) funded by the 16 NIH Institutes and Centers that support the NIH Blueprint for Neuroscience Research; and by the McDonnell Center for Systems Neuroscience at Washington University.

Open Access This article is distributed under the terms of the Creative Commons Attribution 4.0 International License (http://creativeco mmons.org/licenses/by/4.0/), which permits unrestricted use, distribution, and reproduction in any medium, provided you give appropriate credit to the original author(s) and the source, provide a link to the Creative Commons license, and indicate if changes were made.

\section{References}

Albert M, Huttner WB (2015) Clever space saving-how the cerebral cortex folds. EMBO J 34:1845-1847

Alkadhi H, Kollias SS (2004) Pli de passage fronto-pariétal moyen of Broca separates the motor homunculus. AJNR Am J Neuroradiol 25:809-812

Amiez C, Kostopoulos P, Champod AS, Petrides M (2006) Local morphology predicts functional organization of the dorsal premotor region in the human brain. J Neurosci 26:2724-2731

Auzias G, Lefèvre J, Le Troter A, Fischer C, Perrot M, Régis J, Coulon O (2013) Model-driven harmonic parameterization of the cortical surface: HIP-HOP. IEEE Trans Med Imaging 32:873-887

Auzias G, Brun L, Deruelle C, Coulon O (2015) Deep sulcal landmarks: algorithmic and conceptual improvements in the definition and extraction of sulcal pits. Neuroimage 111:12-25

Barch DM et al (2013) Function in the human connectome: task-fMRI and individual differences in behavior. Neuroimage 80:169-189

Bodin C, Pron A, LeMao M, Régis J, Belin P, Coulon O (2019) Plisde-passage within the STS: morphological characterization and underlying connectivity. OHBM, Roma
Bohi A, Wang XY, Al Harrach M, Dinomais M, Rousseau F, Lefèvre J (2019) A framework to study the impact of initial geometry on cortical morphogenesis. OHBM, Roma

Boling WW, Olivier A (2004) Localization of hand sensory function to the pli de passage moyen of Broca. J Neurosurg 101:278-283

Boling W, Olivier A, Bittar RG, Reutens D (1999) Localization of hand motor activation in Broca's pli de passage moyen. J Neurosurg 91:903-910

Borrell V (2018) How cells fold the cerebral cortex. J Neurosci 38:776-783

Borrell V, Calegari F (2014) Mechanisms of brain evolution: regulation of neural progenitor cell diversity and cell cycle length. Neurosci Res 86:14-24

Broca P, Pozzi S (1888) Mémoires sur le cerveau de l'homme et des primates. C. Reinwald, Paris

Cachia A, Roell M, Mangin JF, Sun ZY, Jobert A, Braga L, Houde O, Dehaene S, Borst G (2018) How interindividual differences in brain anatomy shape reading accuracy. Brain Struct Funct 223:701-712

Chen H, Li Y, Ge F, Li G, Shen D, Liu T (2017) Gyral net: a new representation of cortical folding organization. Med Image Anal 42:14-25

Clouchoux C, Riviere D, Mangin JF, Operto G, Regis J, Coulon O (2010) Model-driven parameterization of the cortical surface for localization and inter-subject matching. Neuroimage 50:552-566

Coulon O, Pizzagalli F, Operto G, Auzias G, Delon-Martin C, Dojat M (2011) Two new stable anatomical landmarks on the Central Sulcus: definition, automatic detection, and their relationship with primary motor functions of the hand. Conf Proc IEEE Eng Med Biol Soc 2011:7795-7798

Cunningham DJ (1890a) The complete fissures of the human cerebrum, and their significance in connection with the growth of the hemisphere and the appearance of the occipital lobe. J Anat Physiol 24:309-345

Cunningham DJ (1890b) The fissure of Rolando. J Anat Physiol 25:1-23

Cunningham DJ (1890c) On cerebral anatomy. Br Med J 2:277-283

Cunningham DJ (1892) Contribution to the surface anatomy of the cerebral hemispheres. Royal Irish Academy, Dublin

Cunningham DJ (1897) The Rolandic and Calcarine fissures-a study of the growing cortex of the cerebrum. J Anat Physiol 31:586-598

Cunningham DJ (1903) Textbook of Anatomy. W. Wood and Co., New York

Cykowski MD, Coulon O, Kochunov PV, Amunts K, Lancaster JL, Laird AR, Glahn DC, Fox PT (2008) The central sulcus: an observer-independent characterization of sulcal landmarks and depth asymmetry. Cereb Cortex 18:1999-2009

da Costa Campos L, Elgeti J, Caspers S (2019) On the asymmetry of human brain folding. OHBM, Roma

de Juan Romero C, Bruder C, Tomasello U, Sanz-Anquela JM, Borrell V (2015) Discrete domains of gene expression in germinal layers distinguish the development of gyrencephaly. EMBO J 34:1859-1874

de Vareilles H, Sun Z, Benders M, Fischer C, Leroy F, de Vries L, Groenendaal F, Rivière D, Dubois J, Mangin J-F (2019) Folding dynamics of the Central Sulcus: a longitudinal study on preterms. OHBM, Roma

Duan D, Xia S, Meng Y, Wang L, Lin W, Gilmore JH, Shen D, Li G (2017) Exploring gyral patterns of infant cortical folding based on multi-view curvature information. In: Descoteaux M, MaierHein L, Franz A, Jannin P, Collins D, Duchesne S (eds) Medical image computing and computer assisted intervention - MICCAI 2017, Lecture notes in computer science, vol 10433, p 12-20. Quebec 
Duan D, Xia S, Rekik I, Meng Y, Wu Z, Wang L, Lin W, Gilmore JH, Shen D, Li G (2019) Exploring folding patterns of infant cerebral cortex based on multi-view curvature features: methods and applications. Neuroimage 185:575-592

Dubois J, Benders M, Cachia A, Lazeyras F, Leuchter RH-V, Sizonenko SV, Borradori-Tolsa C, Mangin JF, Hüppi PS (2008) Mapping the early cortical folding process in the preterm newborn brain. Cereb Cortex 18:1444-1454

Eberstaller O (1890) Das Stirnhirn. Urban \& Schwarzenberg, Munich

Feinberg DA, Moeller S, Smith SM, Auerbach E, Ramanna S, Gunther M, Glasser MF, Miller KL, Ugurbil K, Yacoub E (2010) Multiplexed echo planar imaging for sub-second whole brain FMRI and fast diffusion imaging. PLoS ONE 5:e15710

Fischer C, Operto G, Laguitton S, Perrot M, Denghien I, Rivière D, Mangin J-F (2012) Morphologist 2012: the new morphological pipeline of BrainVISA. OHBM, Beijing

Fischl B (2012) FreeSurfer. Neuroimage 62:774-781

Foubet O, Trejo M, Toro R (2018) Mechanical morphogenesis and the development of neocortical organisation. Cortex 118:315-326

Germanaud D, Lefèvre J, Toro R, Fischer C, Dubois J, Hertz-Pannier L, Mangin J-F (2012) Larger is twistier: Spectral analysis of gyrification (SPANGY) applied to adult brain size polymorphism. Neuroimage 63:1257-1272

Germanaud D, Lefèvre J, Fischer C, Bintner M, Curie A, des Portes V, Eliez S, Elmaleh-Bergès M, Lamblin D, Passemard S, Operto G, Schaer M, Verloes A, Toro R, Mangin JF, Hertz-Pannier L (2014) Simplified gyral pattern in severe developmental microcephalies? New insights from allometric modeling for spatial and spectral analysis of gyrification. Neuroimage 102:317-331

Germann J, Robbins S, Halsband U, Petrides M (2005) Precentral sulcal complex of the human brain: morphology and statistical probability maps. J Comp Neurol 493:334-356

Glasel H, Leroy F, Dubois J, Hertz-Pannier L, Mangin JF, DehaeneLambertz G (2011) A robust cerebral asymmetry in the infant brain: the rightward superior temporal sulcus. NeuroImage 58:716-723

Glasser MF, Sotiropoulos SN, Wilson JA, Coalson TS, Fischl B, Andersson JL, Xu J, Jbabdi S, Webster M, Polimeni JR, Van Essen DC, Jenkinson M, Consortium W-MH (2013) The minimal preprocessing pipelines for the Human Connectome Project. Neuroimage 80:105-124

Gratiolet LP (1854) Mémoire sur les plis cérébraux de l'homme et des primates: A. Bertrand, Paris

Heschl R (1877) Die tiefen Windungen des menschlichen Grosshirns und die Uberbrïckung der Centralfurche. Wiener Medicinischer Wochenschrift 41

Heuer K, Toro R (2019) Role of mechanical morphogenesis in the development and evolution of the neocortex. Phys Life Rev. https ://doi.org/10.1016/j.plrev.2019.01.012

Heuer K, Gulban O, Bazin P, Osoianu A, Valabregue R, Santin M, Herbin M, Toro R (2019) Evolution of neocortical folding: a phylogenetic comparative analysis of MRI from 34 primate species. Cortex 118:275-291

Hopkins WD, Coulon O, Mangin JF (2010) Observer-independent characterization of sulcal landmarks and depth asymmetry in the central sulcus of the chimpanzee brain. Neuroscience 171:544-551

Hopkins WD, Meguerditchian A, Coulon O, Bogart S, Mangin JF, Sherwood CC, Grabowski MW, Bennett AJ, Pierre PJ, Fears S, Woods R, Hof PR, Vauclair J (2014) Evolution of the central sulcus morphology in primates. Brain Behav Evol 84:19-30

Huntgeburth SC, Petrides M (2012) Morphological patterns of the collateral sulcus in the human brain. Eur J Neurosci 35:1295-1311
Im K, Grant PE (2019) Sulcal pits and patterns in developing human brains. Neuroimage 185:881-890

Im K, Jo HJ, Mangin J-F, Evans AC, Kim SI, Lee J-M (2010) Spatial distribution of deep sulcal landmarks and hemispherical asymmetry on the cortical surface. Cereb Cortex 20:602-611

Jelgersma G (1889) Ueber den Bau des Saugethiergehirns. Morphologisches Jahrbuch

Jenkinson M, Bannister P, Brady M, Smith S (2002) Improved optimization for the robust and accurate linear registration and motion correction of brain images. Neuroimage 17:825-841

Kostovic I, Rakic P (1990) Developmental history of the transient subplate zone in the visual and somatosensory cortex of the macaque monkey and human brain. J Comp Neurol 297:441-470

Kriegstein A, Noctor S, Martínez-Cerdeño V (2006) Patterns of neural stem and progenitor cell division may underlie evolutionary cortical expansion. Nat Rev Neurosci 7:883-890

Kroenke CD, Bayly PV (2018) How forces fold the cerebral cortex. J Neurosci 38:767-775

Kruggel F (2018) The macro-structural variability of the human neocortex. Neuroimage 172:620-630

Le Guen Y, Auzias G, Leroy F, Noulhiane M, Dehaene-Lambertz G, Duchesnay E, Mangin JF, Coulon O, Frouin V (2018a) Genetic influence on the sulcal pits: on the origin of the first cortical folds. Cereb Cortex 28:1922-1933

Le Guen Y, Leroy F, Auzias G, Riviere D, Grigis A, Mangin JF, Coulon O, Dehaene-Lambertz G, Frouin V (2018b) The chaotic morphology of the left superior temporal sulcus is genetically constrained. Neuroimage 174:297-307

Lefèvre J, Leroy F, Khan S, Dubois J, Huppi P, Baillet S, Mangin JF (2009) Identification of growth seeds in the neonate brain through surfacic Helmholtz decomposition. Information Processing in Medical Imaging. Springer, Berlin, pp 252-263

Lefèvre J, Germanaud D, Dubois J, Rousseau F, de Macedo Santos I, Angleys H, Mangin JF, Hüppi PS, Girard N, De Guio F (2015) Are developmental trajectories of cortical folding comparable between cross-sectional datasets of fetuses and preterm newborns? Cereb Cortex 26:3023-3036

Leroy F et al (2015) New human-specific brain landmark: the depth asymmetry of superior temporal sulcus. Proc Natl Acad Sci USA 112:1208-1213

Llinares-Benadero C, Borrell V (2019) Deconstructing cortical folding: genetic, cellular and mechanical determinants. Nat Rev Neurosci 20:161-176

Lohmann G, von Cramon DY (2000) Automatic labelling of the human cortical surface using sulcal basins. Med Image Anal 4:179-188

Lohmann G, von Cramon DY, Colchester AC (2008) Deep sulcal landmarks provide an organizing framework for human cortical folding. Cereb Cortex 18:1415-1420

Lui JH, Hansen DV, Kriegstein AR (2011) Development and evolution of the human neocortex. Cell 146:18-36

Makropoulos A et al (2018) The developing human connectome project: a minimal processing pipeline for neonatal cortical surface reconstruction. Neuroimage 173:88-112

Mangin JF, Régis J, Poupon C, Pachot-Clouart M, Belin P, Bihan DL, Frouin V (1998) The duality between sulcal roots and U-fiber bundles investigated via tensor diffusion imaging. In: Proc. 4th OHBM, NeuroImage, Elsevier, Montreal

Mangin J, Riviere D, Coulon O, Poupon C, Cachia A, Cointepas Y, Poline J, Le Bihan D, Regis J, Papadopoulos-Orfanos D (2004) Coordinate-based versus structural approaches to brain image analysis. Artif Intell Med 30:177-197

Mangin J-F, Auzias G, Coulon O, Sun ZY, Rivière D, Régis J (2015a) Sulci as landmarks. In: Toga AW (ed) Brain mapping: an encyclopedic reference. Academic Press, Elsevier, New York, pp $45-52$ 
Mangin J-F, Perrot M, Operto G, Cachia A, Fischer C, Lefèvre J, Rivière D (2015b) Sulcus identification and labeling. In: Toga AW (ed) Brain mapping: an encyclopedic reference. Academic Press, Elsevier, New York, pp 365-371

Mangin JF, Lebenberg J, Lefranc S, Labra N, Auzias G, Labit M, Guevara M, Mohlberg H, Roca P, Guevara P, Dubois J, Leroy F, Dehaene-Lambertz G, Cachia A, Dickscheid T, Coulon O, Poupon C, Rivière D, Amunts K, Sun ZY (2016) Spatial normalization of brain images and beyond. Med Image Anal 33:127-133

Marcus DS, Harwell J, Olsen T, Hodge M, Glasser MF, Prior F, Jenkinson M, Laumann T, Curtiss SW, Van Essen DC (2011) Informatics and data mining tools and strategies for the human connectome project. Front Neuroinform 5:4

McKay DR, Kochunov P, Cykowski MD, Kent JW, Laird AR, Lancaster JL, Blangero J, Glahn DC, Fox PT (2013) Sulcal depthposition profile is a genetically mediated neuroscientific trait: description and characterization in the central sulcus. J Neurosci 33:15618-15625

Meng Y, Li G, Lin W, Gilmore JH, Shen D (2014) Spatial distribution and longitudinal development of deep cortical sulcal landmarks in infants. Neuroimage 100:206-218

Moeller S, Yacoub E, Olman CA, Auerbach E, Strupp J, Harel N, Uğurbil K (2010) Multiband multislice GE-EPI at 7 tesla, with 16-fold acceleration using partial parallel imaging with application to high spatial and temporal whole-brain fMRI. Magn Reson Med 63:1144-1153

Mota B, Herculano-Houzel S (2015) BRAIN STRUCTURE. Cortical folding scales universally with surface area and thickness, not number of neurons. Science 349:74-77

Ochiai T, Grimault S, Scavarda D, Roch G, Hori T, Riviere D, Mangin JF, Regis J (2004) Sulcal pattern and morphology of the superior temporal sulcus. Neuroimage 22:706-719

Ono M, Kubik S, Abarnathey CD (1990) Atlas of the cerebral sulci. Georg Thieme, New York

Ortinau CM, Rollins CK, Gholipour A, Yun HJ, Marshall M, Gagoski B, Afacan O, Friedman K, Tworetzky W, Warfield SK, Newburger JW, Inder TE, Grant PE, Im K (2018) Early-emerging sulcal patterns are atypical in fetuses with congenital heart disease. Cereb Cortex. https://doi.org/10.1093/cercor/bhy235

Parent A (2014) Louis Pierre Gratiolet (1815-1865) and his contribution to the study of the cerebral convolution in Primates. Neurosci Med. https://doi.org/10.4236/nm.2014.51001

Plaze M, Mangin JF, Paillère-Martinot ML, Artiges E, Olié JP, Krebs MO, Gaillard R, Martinot JL, Cachia A (2015) "Who is talking to me?" Self-other attribution of auditory hallucinations and sulcation of the right temporoparietal junction. Schizophr Res 169:95-100

Pron A, Brun L, Deruelle C, Coulon O (2018) Dense and structured representations of U-shape fiber connectivity in the central sulcus. In: 15th International Symposium on Biomedical Imaging, pp 700-703

Régis J (1994) Deep sulcal anatomy and functional mapping of the cerebral cortex (in French). MD Thesis, Universite d'Aix-Marseille

Regis J, Mangin JF, Frouin V, Remy P, Rey M, Peragut JC, Samson Y, Chauvel P (1997) Toward Better Management of Cortical Anatomy in Epilepsy Surgery. Stereotact Funct Neurosurg 68:247-247

Regis J, Mangin J, Ochiai T, Frouin V, Riviere D, Cachia A, Tamura M, Samson Y (2005) "Sulcal root" generic model: a hypothesis to overcome the variability of the human cortex folding patterns. Neurol Med Chir 45:1-17

Reillo I, de Juan Romero C, García-Cabezas M, Borrell V (2011) A role for intermediate radial glia in the tangential expansion of the mammalian cerebral cortex. Cereb Cortex 21:1674-1694
Richman DP, Stewart RM, Hutchinson JW, Caviness VS (1975) Mechanical model of brain convolutional development. Science 189:18-21

Sastre-Janer FA, Regis J, Belin P, Mangin J-F, Dormont D, Masure M-C, Remy P, Frouin V, Samson Y (1998) Three-dimensional reconstruction of the human central sulcus reveals a morphological correlate of the hand area. Cereb Cortex 8:641

Schweizer R, Helms G, Frahm J (2014) Revisiting a historic human brain with magnetic resonance imaging - the first description of a divided central sulcus. Front Neuroanat 8:35

Schweizer R, Muellen A, Frahm J (2019) Location and height of the central sulcus pli de passage frontoparietal moyen in a large cohort. OHBM, Roma

Segal E, Petrides M (2012) The morphology and variability of the caudal rami of the superior temporal sulcus. Eur J Neurosci 36:2035-2053

Sernoff (1887) A rare case of change of form of the Rolandic furrow and central convolutions. Academy House, Moskow

Snyder W, Patti M, Troiani V (2019) An evaluation of automated tracing for orbitofrontal cortex sulcogyral pattern typing. J Neurosci Methods 326:108386

Sprung-Much T, Petrides M (2018) Morphological patterns and spatial probability maps of two defining sulci of the posterior ventrolateral frontal cortex of the human brain: the sulcus diagonalis and the anterior ascending ramus of the lateral fissure. Brain Struct Funct 223:4125-4152

Steinmetz H, Ebeling U, Huang YX, Kahn T (1990) Sulcus topography of the parietal opercular region: an anatomic and MR study. Brain Lang 38:515-533

Striedter GF, Srinivasan S, Monuki ES (2015) Cortical folding: when, where, how, and why? Annu Rev Neurosci 38:291-307

Sun ZY, Rivière D, Poupon F, Régis J, Mangin JF (2007) Automatic inference of sulcus patterns using 3D moment invariants. Med Image Comput Comput Assist Interv 10:515-522

Sun ZY, Perrot M, Tucholka A, Rivière D, Mangin JF (2009) Constructing a dictionary of human brain folding patterns. In: Yang GZ, Hawkes D, Rueckert D, Noble A, Taylor C (eds) Medical image computing and computer-assisted intervention - MICCAI 2009, Lecture notes in computer science, vol 5762, p 117-124. Springer, Berlin

Sun ZY, Pinel P, Rivière D, Moreno A, Dehaene S, Mangin JF (2016) Linking morphological and functional variability in hand movement and silent reading. Brain Struct Funct 221:3361-3371

Sun ZY, Cachia A, Rivière D, Fischer C, Makin TR, Mangin J-F (2017) Congenital unilateral upper limb absence flattens the contralateral central sulcus. OHBM, Toronto

Sun ZY, Rivière D, Fischer C, Grigis A, Poupon C, Mangin J-F (2019) Manifold-based exploration of the links between cortical morphology and functional architecture. OHBM, Roma

Sur M, Rubenstein JL (2005) Patterning and plasticity of the cerebral cortex. Science 310:805-810

Tallinen T, Chung JY, Biggins JS, Mahadevan L (2014) Gyrification from constrained cortical expansion. Proc Natl Acad Sci USA 111:12667-12672

Tallinen T, Chung JY, Rousseau G, Girard N, Lefèvre J, Mahadevan L (2016) On the growth and form of cortical convolutions. Nat Phys 12:588-593

Toro R, Burnod Y (2003) Geometric atlas: modeling the cortex as an organized surface. Neuroimage 20:1468-1484

Toro R, Burnod Y (2005) A morphogenetic model for the development of cortical convolutions. Cereb Cortex 15:1900-1913

Toro R, Perron M, Pike B, Richer L, Veillette S, Pausova Z, Paus $\mathrm{T}$ (2008) Brain size and folding of the human cerebral cortex. Cereb Cortex 18:2352-2357 
Van Essen DC (1997) A tension-based theory of morphogenesis and compact wiring in the central nervous system. Nature 385:313-318

Van Essen DC et al (2012) The Human Connectome Project: a data acquisition perspective. Neuroimage 62:2222-2231

Van Essen DC, Smith SM, Barch DM, Behrens TE, Yacoub E, Ugurbil K, Consortium W-MH (2013) The WU-Minn Human Connectome Project: an overview. Neuroimage 80:62-79

Wagner H (1864) Maasbestimmungen der Oberfläche des grossen Gehirns.: Göttingen: Cassel Trömmer \& Dietricht

Wang X, Studholme C, Grigsby PL, Frias AE, Cuzon Carlson VC, Kroenke CD (2017) Folding, but not surface area expansion, is associated with cellular morphological maturation in the fetal cerebral cortex. J Neurosci 37:1971-1983

Welker W (1988) Why does cerebral cortex fissure and fold? Cereb Cortex 8B:3-135

White LE, Andrews TJ, Hulette C, Richards A, Groelle M, Paydarfar J, Purves D (1997) Structure of the human sensorimotor system. I: morphology and cytoarchitecture of the central sulcus. Cereb Cortex 7:18-30
Woolrich MW, Ripley BD, Brady M, Smith SM (2001) Temporal autocorrelation in univariate linear modeling of FMRI data. Neuroimage 14:1370-1386

Xia J, Wang F, Benkarim OM, Sanroma G, Piella G, González Ballester MA, Hahner N, Eixarch E, Zhang C, Shen D, Li G (2019) Fetal cortical surface atlas parcellation based on growth patterns. Hum Brain Mapp 40:3881-3899

Yousry TA, Schmid UD, Alkadhi H, Schmidt D, Peraud A, Buettner A, Winkler P (1997) Localization of the motor hand area to a knob on the precentral gyrus. A new landmark. Brain $120(\mathrm{Pt}$ 1):141-157

Zlatkina V, Petrides M (2010) Morphological patterns of the postcentral sulcus in the human brain. J Comput Neurol 518:3701-3724

Zlatkina V, Amiez C, Petrides M (2016) The postcentral sulcal complex and the transverse postcentral sulcus and their relation to sensorimotor functional organization. Eur J Neurosci 43:1268-1283

Publisher's Note Springer Nature remains neutral with regard to jurisdictional claims in published maps and institutional affiliations. 